\title{
North American Fire Weather Catalyzed by the Extratropical Transition of Tropical Cyclones
}

Jacob John Stuivenvolt Allen ( $\square$ jacob.stu.allen@gmail.com )

Utah State University College of Agriculture and Applied Sciences https://orcid.org/0000-0002-2611$284 X$

\section{S.-Y. Simon Wang}

Utah State University College of Agriculture and Applied Sciences

\section{Research Article}

Keywords: Fire weather, tropical cyclones, Rossby waves, compounding extremes, typhoons

Posted Date: August 4th, 2021

DOl: https://doi.org/10.21203/rs.3.rs-740651/v1

License: (1) This work is licensed under a Creative Commons Attribution 4.0 International License. Read Full License 


\section{Abstract}

When tropical cyclones in the western North Pacific turn into midlatitude cyclones, it often perturbs the jet stream, resulting in amplified flow conditions in the north Pacific and various weather extremes in North America. Thus far, however, the complex impacts of extratropical transitioning cyclones (ETCs) on North American fire weather are undocumented. In this study, we group ETCs by the characteristics that are important for their interaction with the jet stream and document the response in North American fire weather, finding that ETCs are consistently associated with enhanced fire weather in North America through amplified pressure gradients and anomalous winds. While the chaotic nature of the ETC and jet stream interaction means that ETCs grouped by similar characteristics and locations can result in varying downstream responses, the composite analysis reveals some areas of consistently enhanced fire weather, including the Pacific Northwest and northern Intermountain West. At a time in which the risk and extent of wildfires in the Western United States is an issue of growing concern, this study represents the first holistic understanding of how ETCs' downstream perturbations impact fire weather.

\section{Introduction}

The peak of tropical cyclone activity and associated interactions with the jet stream (Archambault et al., 2013; Balch et al., 2017), from July through October, coincides with the peak fire season in the western North America. While the actual ignition and ecological precursors for fire (i.e. fuel load, seasonal drought) are mostly independent of the impact of typhoons: winds, humidity and temperature in the western US can be significantly impacted by amplified flow due to upstream typhoons (Stuivenvolt-Allen et al., 2021; Bosart et al., 2017; Grams et al., 2013). September of 2020 was a notable example of how the extratropical flow response to tropical cyclones can result in catastrophic fire outbreaks and spread. Days before the fire outbreak in the Pacific Northwest on the 8th of September, three typhoons made an extratropical transition near the Korean peninsula in quick succession, resulting in a Rossby wave train across the north Pacific. Subsequently, a strengthened pressure gradient formed directly over the Pacific Northwest resulting in record-breaking winds and rapid fire spread throughout the region (Stuivenvolt Allen et al., 2021). Research has shown that typhoons interacting with the jet stream can result in downstream weather extremes (Bosart et al., 2017), but the relationship between tropical cyclones and fire weather has not been examined holistically. As such, our objective is to create composites of western North Pacific tropical cyclones and their extratropical interaction to examine their relationship with enhanced fire weather in western North America.

The mechanisms underlying a typhoon and jet stream interaction have been extensively studied. Extratropical transitioning cyclones (ETCs)-defined as a tropical cyclone that travels into the midlatitudes and re-intensifies as a cold core extratropical cyclone-have the most potential for causing lasting and energetic flow amplification in the North Pacific, though recurving typhoons which do not transition also result in amplified flow patterns (Agustí-Panareda et al., 2005; Archambault et al., 2013; Harr \& Dea, 2009; Hodyss \& Hendricks, 2010; Pantillon et al., 2013). As an immense source of diabatic heating, ETCs facilitate the advection of low potential vorticity (PV) into the jet region, resulting in a 
localized ridge and an intensified jet streak to the north of the ETC (Evans et al., 2017; Grams et al., 2015; Riemer \& Jones, 2010). This process catalyzes extratropical cyclogenesis adjacent to the jet streak and the associated Rossby wave energy dispersion results in an alternating atmospheric wave train which spans across the entire north Pacific (Archambault et al., 2013, 2015; Orlanski \& Sheldon, 1995).

The interaction between an ETC and the north Pacific wave guide changes with respect to the seasonality, intensity and position of an ETC. In summary, these findings highlight that the north Pacific flow in August, September and October is most conducive for amplification due to tropical cyclone-jet interactions (Archambault et al., 2013). From July to October, ETCs become stronger by both measures of central mean sea level pressure (MSLP) and the radius of $30 \mathrm{kt}$ winds at recurvature. The longitudinal position of recurvature is also a critical component for determining the strength of the ETC-extratropical flow interaction, with stronger interactions occurring with ETCs that recurve farther west (Archambault et al., 2013). The large variability of storm characteristics (position, intensity, and seasonality) is one component of the extratropical flow interaction, as the characteristics of the north Pacific flow at the time of recurvature are also important for determining whether the ETC's impact is constructive. Specifically, if an ETC becomes phase locked with an approaching trough, meaning the ETC and the trough converge in space and time, the impact of the ETC is resonant with the existing wave structure-resulting in a more energetic downstream responses (Aiyyer, 2015; Grams et al., 2015; Riboldi et al., 2019). Additionally, the intensity and position of the subtropical jet stream impacts the amplitude of the downstream wave response, with more intense jet speeds resulting in greater wave amplification (Finocchio \& Doyle, 2019). These factors which influence the relationship between a typhoon and amplified flow will be analyzed to determine if enhanced fire weather in North America changes in response to ETC characteristics.

The existing knowledge of ETCs and recurving typhoons highlights that subsequent analysis of the fire weather response to ETCs must account for seasonal variability in the midlatitude flow, along with the spatial and intensity variability of an ETC. Due to the potential for amplified flow to greatly impact fire spread and intensity, we aim to group ETC events into categories that are important for their associated impacts to analyze the response of North American fire weather. Using the Canadian Fire Weather Index, a fire severity rating that depends on fuel moisture and weather conditions (Wagner et al., 1987), we will determine how different ETC characteristics impact the likelihood of enhanced fire weather.

\section{Methods}

\subsection{Data:}

For the record of typhoon position, timing, intensity and classification, we use the Japanese Meteorological Agency's (JMA) Best Track Dataset which is provided by the Regional Specialized Meteorological Center (https://www.jma.go.jp). This dataset has been shown to accurately represent typhoon intensity and position and has been used in many analyses of the extratropical flow response to typhoons (Archambault et al., 2013, 2015; Barcikowska et al., 2012). The response of the atmosphere to ETCs will be analyzed using the National Center for Environmental Prediction-Department of Energy's 
Reanalysis 2 (NCEP R2) at six-hour intervals (Kanamitsu et al., 2002). As the diabatic outflow from a tropical cyclone is prominent in the upper level, we will use daily geopotential height at $200 \mathrm{hPa}(\mathrm{z} 200)$ to analyze the impact of the ETC on recurvature. We use daily data to match the format of the FWI described below. For evaluating the strength of the ETC and jet interaction, we compute potential vorticity advection using the European Centre for Medium-Range Weather Forecasts ERA5 global reanalysis data as the diabatic outflow of an ETC will be better captured with the $0.25^{\circ}$ resolution (Hersbach et al., 2020). PV advection is calculated at the closest six-hour interval to T0, a reference time for each ETC described in Sect. 2.3.

To determine the likelihood of fire weather conditions after the recurvature of a western Pacific typhoon, we use the Modern-Era Retrospective Analysis for Research and Applications Version 2 (MERRA2) reanalysis dataset (Gelaro et al., 2017). MERRA2 contains a daily Fire Weather Index (FWI) which is a component of the Canadian Forest Fire Weather Index System. The FWI used in this study takes MERRA2's temperature, relative humidity, wind speed and 24-hour precipitation to provide numeric ratings for the potential of wildland fire (Van Wagner et al., 1987). The FWI comes from an integration of an Initial Spread Index (ISI) - which comprises temperature, relative humidity, rain and wind data-and a Buildup Index (BUI) which uses temperature, relative humidity and rain. Details on the calculation of each index can be found in Van Wagner et al. (1987). With wind only included in the ISI, we will use the ISI and $\mathrm{BUI}$ to provide diagnostic analysis on whether enhanced fire conditions associated with typhoons are more driven by wind or moisture deficits and temperature.

\subsection{Typhoon classification:}

We include tropical cyclones from 1979 through 2020 which reached a tropical storm classification (sustained winds greater than $62 \mathrm{~km} / \mathrm{hr}$ ) and an extratropical cyclone classification by the JMA. This ensures that each typhoon in our analysis had interactions with the extratropical flow. The start date is chosen as 1979 because the Best Track Data started classifying typhoons which became extratropical low-pressure systems in 1977, making categorical grouping of typhoons more efficient and objective, and this period overlaps with satellite era reanalysis data as well. The reference point used to view the timelagged impact of an ETC is defined as the point in which an ETC passes $30^{\circ} \mathrm{N}$. As it has been shown that an ETC may start to impact the jet region before the extratropical transition (Stuivenvolt-Allen et al., 2021), this latitude threshold produced more clearly defined wave trains in the composite maps than selecting the point of ETC recurvature (not shown). The latitude requirement also reduces the potential for the composite maps to contain lower-latitude/tropical forcing mechanisms similar to the Pacific-North America teleconnection (Wallace et al., 1993). A latitude requirement for the reference time-step (T0) also results in better defined atmospheric wave trains (shown later).

\subsection{Composite analysis:}

To delineate the general impact of typhoons on fire weather and geopotential height at $200 \mathrm{hPa}(\mathrm{z} 200)$, we create composite maps of FWI and z200 anomalies. These composites are displayed at lag times two days after the day in which an ETC passed $30^{\circ} \mathrm{N}$, which will be referred to as TO. As the atmospheric 
upper-level flow is most amplified about two to three days after typhoon recurvature in the north Pacific (Archambault et al., 2013), this lag time most effectively captures the amplified pressure field and potential for enhanced fire weather. Additionally, ETCs are grouped by July through August (JA) and September through October (SO) so that the seasonal characteristics of the jet stream and ETCs are separated. Finally, to reduce smearing effects in the composite maps due to differences in the ETC location, each composite is grouped by the interquartile range (IQR) of T0 longitude. This allows for the comparison of equitable sample sizes and results in groups of ETCs that occurred within similar locations.

Anomalies in the geopotential height field are defined as the difference between the daily long-term mean, calculated from 1990 through 2021. For the FWI, anomalies are defined as the difference in FWI two days after T0 by the FWI two days before T0. This shows the change in FWI in response to the ETC amplified flow. This differencing method helps remove enhanced fire weather conditions that may have existed before TO and independent of the ETC.

\section{Results}

\subsection{Impact of typhoon position and season on downstream fire weather}

The methodology of our typhoon classification is shown in Fig. 1, with the track density of the typhoon trajectories for July through October. This shows that the heaviest density of ETCs occurs just south of Japan, but ETCs span a longitudinal range from $120^{\circ} \mathrm{E}$ to about $170^{\circ} \mathrm{E}$. Also plotted in Fig. 1 is the climatological FWI distribution in North America from July through October, showing that the Southwest United States has a consistently high FWI through these months. The FWI is a unitless and open-ended index, so the climatology also serves as a reference point for the subsequent analysis. The positions of the long-term mean jet stream cores in JA and SO are shown in the contours. While the position of the jet stream does not experience a major shift from JA to SO, the jet intensity is notably higher for SO. Due to the ability of jet intensity to modulate the downstream wave train (such as the effective wave number or the amplified flow potential), all future analysis will be split into the two seasons to better isolate the signal associated with an ETC (Ding \& Wang, 2005; Finocchio \& Doyle, 2019).

To avoid smearing of the $z 200$ and FWI fields in the subsequent composite analysis, typhoons are grouped into four longitudinal bins based off of their IQR. The first three longitudinal bins (shown as gray rectangles in Fig. 2) each contain $25 \%$ of the ETCs used in this analysis for the respective season. The fourth longitudinal bin, which contains the largest range, is limited to be $10^{\circ}$ greater than the $3 \mathrm{rd}$ quartile, to once again limit smearing effects of the composites. The IQR is computed for ETCs in JA, and again for SO due to the seasonal shifts of recurving typhoons, with the position of recurvature generally shifting toward the equator and eastward July through September (Archambault et al., 2013).

To evaluate the efficacy of this longitudinal grouping and of the selection of the T0 start time, Fig. 2 displays the composite z200 anomalies for the day following T0. To the northeast of each T0 point (the longitudinal IQRs are shown by gray rectangles), enhanced ridging is occurring due to the diabatic 
outflow of each ETC. Adjacent to the localized ridge produced by the ETC is extratropical cyclogenesis and the formulation of a Rossby wave train across the North Pacific. It is notable that the $z 200$ anomalies are more pronounced for SO, which is likely a product of the stronger jet for this season (Finocchio \& Doyle, 2019). In summary, the longitudinal and seasonal grouping of typhoons effectively produces the circulation features expected for the initial interaction of a ETC with the jet region. Additionally, we can see the wave packet associated with ETC is impacted by the longitudinal position of recurvature.

To evaluate the seasonal differences in the downstream FWI response to ETCs, Fig. 3 shows the composite anomalies two days after T0 for July through August ETCs for each longitudinal position (Figs. 3a-d), alongside September to October ETCs (Fig. 3e-h) for z200 and FWI. The FWI shown is the difference from before T0 to after T0 in order to eliminate pre-existing fire weather that may bleed into the composites. For JA, the z200 composite response depicts an enhanced ridge over the Gulf of Alaska, with a negative pressure anomaly over the west coast of the US. Even with changes in the longitudinal position of T0, z200 anomalies three to four days after T0 are only marginally shifted over North America (Fig. 3a-3d). The most notable and widespread increase in FWI is associated with the second and third longitudinal IQR shown in Figs. 3b and c. However, other longitudinal groupings show localized regions of enhanced FWI under low pressure anomalies, frontal boundaries, and regions of high pressure. The downstream response in SO shows z200 anomalies that are shifted east compared to JA (Fig. 3e-h). The ridge location adjacent to North America also appears more sensitive to the longitude of recurvature for SO, with the maximum downstream ridge shifting more dramatically east along with the longitude of T0 (most notable in Figs. 3e-g). Areas of enhanced FWI are seen scattered along frontal boundaries and in areas ahead of low-pressure, suggesting that the enhanced fire weather conditions associated with ETCs may be linked to wind events rather than rapid temperature or humidity changes alone.

The composite analysis highlights that fire weather responses in North America are localized and scattered. Some composites do not result in any statistically robust areas of enhanced fire weather (e.g., Fig. 3f). However, the composites do not provide much insight into the spread or variability within each composite group. Therefore, we show 25 of the composite members in Fig. 4, selected at random, which are included in Fig. 3b. ETCs which recurve in the same longitudinal location can produce different downstream responses, noted by the large variance in z200 and FWI response in Fig. 4. As a result, FWI anomalies are not consistent based on the grouping of ETCs, though the boxed regions roughly highlight areas where the composite analysis resulted in enhanced FWI anomalies (Fig. 2b). Most circulation features are also consistent, with a negative pressure anomaly commonly featured just off or over the western coast of North America. Amplified FWI is often seen on the southwest axis of a trough, likely because of anomalous winds around the frontal boundary.

Figure 5 shows 25 random members of the composite for the 2 nd longitudinal IQR in SO. While the composite average shows almost no significantly different areas of enhanced FWI following T0, we can see that individual members are associated with considerably enhanced FWI. However, there is little agreement on the precise region of positive FWI changes for this grouping of ETCs. Similar to the cases in Fig. 4, we can see enhanced FWI under high pressure at frontal boundaries. This highlights the 
difficulty of synthesizing general impacts of ETCs on fire weather, as ETCs which occur in similar seasons and at similar locations can have divergent downstream impacts.

\subsection{Impact of ETC strength}

Archambault et al. (2013) also showed that stronger ETCs, by measure of their central MSLP and the radius of the $30 \mathrm{kt}$ winds, produce a more amplified flow response. Consistent with this finding, we show the intensity of an ETC has an impact on the interaction with the jet region and the subsequent amplitude of the local ridge amplification due to an ETC (Fig. 6). Especially notable in the ETCs which occur in SO, Fig. 6 shows that ETCs which have lower central MSLP while passing $30^{\circ} \mathrm{N}$ produce a more amplified local response than ETCs with higher central MSLPs. These differences are only noticeable for the z200 anomalies in the western Pacific, while the eastern north Pacific $\left(150^{\circ} \mathrm{W}-110^{\circ} \mathrm{W}\right)$ shows a less coherent response to ETC based on MSLP. It is possible that this composite analysis better depicts the western North Pacific z200 response to an ETC, but the z200 anomalies in the eastern Pacific which are further away from the initial perturbation may become more divergent. Subsequently, there is not a clear relationship between ETC MSLP at T0 and the downstream fire weather. While regions of anomalously high FWI are still captured in Fig. 6 (most common at frontal boundaries and the southern extent of lowpressure anomalies), comparing the group of strong and weak ETCs shows that intensity does not consistently impact the FWI response. The composites for JA produce analogous results and are shown in Figure S1.

\subsection{Impacts of the jet stream interaction}

While the position and timing of ETCs within the seasonal cycle has been shown to have an effect on the magnitude of north Pacific flow amplification (Archambault et al., 2013; Evans et al., 2017), our composite analysis has highlighted that these seasonal and location characteristics do not consistently alter the realization of fire weather at any one location in North America. It is possible that our grouping of ETCs does not account for critical factors which influence the exact position of synoptic features-the location of z200 anomalies and frontal zones. Literature about ETC impacts on north Pacific flow regimes has also shown that the background conditions in which an ETC is born are fundamental for the potential of amplified flow. In particular, an ETC is more likely to result in downstream impacts if the interaction with the mid latitude flow is constructive--meaning the ETC can amplify already existing wave trains or synoptic pressure patterns (Evans et al., 2017; Jones et al., 2003). Additionally, the impact of an ETC is greater when the interaction with the jet stream is stronger (Archambault et al., 2013, 2015). The potential vorticity (PV) framework is commonly utilized to analyze the interaction between an ETC and the jet, as the diabatic heating from an ETC results in low PV advection into the jet region which is considered the initial perturbation that eventually results in a Rossby wave train across the Pacific. The strength of the ETC and jet interaction can therefore be characterized using the PV framework, where strong interactions result in more widespread and negative values of PV advection into the jet region (approximately 200hPa in summer) (Bosart et al., 2017; Bosart \& Lackmann, 1995; Molinari et al., 1997). 
Figure 7 shows the response of grouping cases of ETCs by the strength of their interaction with the jet stream upon extratropical transition for JA. The 200hPa PV advection is computed for the time step in which an ETC was first categorized as an extratropical low-pressure system. To quantify the interaction, the negative PV advection was summed within a domain surrounding the location of the ETC central pressure anomaly $\left(20^{\circ} \mathrm{W}\right.$ to $20^{\circ} \mathrm{E}$ and $5^{\circ} \mathrm{S}$ to $20^{\circ} \mathrm{N}$ of the ETC). The domain was chosen by plotting cases of negative PV advection and selecting a boundary that captured the entire impact of the ETC. After determining the median negative PV advection from all cases, the ETCs are separated into strong (more negative PV advection) and weak (less negative PV advection) groups. In Fig. 7, the composite PV advection for the ETCs which had strong interactions with the jet stream depicts broader and more negative PV advection. The maximum point of interaction is to the northwest of the center of each ETC. The SO interactions are notably more intense which may be a product of enhanced jet stream speeds for these months (Finocchio \& Doyle, 2019).

In the cases with a more energetic interaction with the jet stream, the local ridge amplified directly by an ETC is of slightly higher amplitude for each longitudinal grouping. However, the wave train in z200 for both the strong and weak jet interactions are not clearly distinct for JA, and neither is the associated fire weather. The black rectangles highlight regions from the seasonal composite (Fig. 3) which contained consistently amplified FWI. Positive FWI anomalies still exist in these locations for both the strong and weak jet interactions, showing that for JA the strength of the interaction doesn't significantly alter the realization of downstream fire weather.

The composites for SO in Fig. 9 are analogous to Fig. 8, but the downstream flow is more amplified for the later season composites. The stronger jet interactions (9a-d) result in a more amplified local ridge than the weak interactions (Fig. 9e-h). The broad area of enhanced FWI in Fig. 3d, shown with the black rectangle, is more holistically represented by the composites with the weak interactions (Fig. 9h). This highlights that downstream fire weather is still modulated by relatively weak ETCs with relatively week jet stream interactions.

\subsection{Mechanisms driving enhanced fire weather}

Figure 10 investigates the mechanism in which the amplified flow regime from an ETC can enhance North American fire weather for JA. The Initial Spread Index (ISI) represents the component of the FWI that is related to wind in combination with temperature and relative humidity, while the Buildup Index (BUI) only represents the impact on fire fuel through temperature, relative humidity and rain (Wagner et al., 1987). In comparing the spatial pattern of enhanced FWI with the ISI and BUI, it is clear that the ISI spatially mimics that of the FWI two days after an ETC. This supports that the amplified flow regime is important for fire weather due to the enhanced pressure gradients and deepened low-pressure systems, resulting in anomalous wind during a climatologically dry season. However, the BUI also shows that the impact of an ETC on fire weather or the likelihood of fire is not constrained to the lifetime of an ETC. While anomalous winds associated with low-pressure and frontal zones can increase the likelihood of fire spread, the adjacent ridge results in increased temperature and decreased humidity which may increase 
the likelihood of fire in the near future. Notably, the BUI consistently shows positive anomalies along the west coast and in California, suggesting that ETCs and their associated teleconnection contribute to decreasing fuel and soil moisture in this region. The JA composites also show that the amplified flow conditions associated with an ETC produce broad areas of enhanced fire risk. However, the FWI response does not shift eastward with respect to the changing longitudinal grouping. In general, the Pacific Northwest and the northern Intermountain West regions result in the most consistently enhanced FWI and $\mathrm{BUI}$ response when there is ETC present.

The composites from SO generally support the findings from JA, though the areas of enhanced FWI are more localized than JA. This can be partially explained by the composite members in Fig. 5 which show more spatial variance in the FWI following an ETC. The SO composite still shows that the spatial pattern of the ISI more closely matches the spatial pattern of enhanced fire weather, supporting the observation that increased winds drive enhanced FWI (Fig. 11).

\section{Discussion And Conclusions}

Western North Pacific ETCs have been extensively documented for their impact on amplified flow regimes and extreme weather events in North America, most notably cold-air outbreaks and precipitation extremes (Bosart et al., 2017; Grams et al., 2013; Jones et al., 2003). We have shown that these impacts include enhanced fire weather conditions for much of North America as well, made likely by the simultaneous occurrence of peak ETC and fire seasons. However, composite analysis of ETCs and their associated fire weather conditions highlights that the downstream response to ETCs is chaotic and varied. ETCs which occur in the same region and season can produce different downstream responses due to minor shifts in the north Pacific Wave train. Fire weather in particular is often enhanced on small scales and over small geographic features, due to the heterogenous distribution of forests and fuels and topographical impacts on surface winds (Krawchuk et al., 2016). As a result, small shifts in the amplified flow pattern can cause large shifts in the location and intensity of anomalous fire weather conditions.

We conclude that the impact of an ETC on fire weather is most prominently caused by enhanced wind associated with amplified pressure gradients, as the wind-driven fire index (ISI) closely matches the FWI. However, the position of ridging in the north Pacific wave train is also a catalyst for enhanced fire weather, as anomalously hot and dry conditions can result in more fire-prone fuel loads and vapor pressure deficits (Keen et al., 2020; Seager et al., 2015). The composite analysis also highlights that the Pacific Northwest and the upper Intermountain West have the most consistent fire weather response to ETCs. The climatology of FWI in Fig. 1 shows that these regions have a lower fire weather risk compared to the Southwest United States, but the impact of an ETC can result in anomalous spikes in fire weather. This might be caused by the varied topography in these regions, with amplified pressure patterns often resulting in dry, downsloping winds (Stuivenvolt-Allen et al., 2021; Mass \& Ovens, 2019).

With the well-documented increase in wildfire severity and intensity, largely a result of climate change, forest management practices and shifts in ignition to more anthropogenic causes (Abatzoglou \& 
Williams, 2016; Balch et al., 2017; Collins et al., 2019; Harvey, 2016; Holden et al., 2018; Jain et al., 2017; Westerling, 2016; Yoon et al., 2015), the relationship between ETCs and actual fire events could be changing. Even without the impact of climate change, upstream perturbations might exacerbate already enhanced fire conditions that are caused by internal climate variability that produces drought conditions (Gedalof, 2011; Schoennagel et al., 2007; Westerling \& Swetnam, 2003). Additionally, ETCs have been shown to decrease forecast skill for about a week after recurvature, a direct influence on tools that are crucial for fighting and containing existing fires (Aiyyer, 2015; Grams et al., 2015; Jones et al., 2003).

The findings of this study are limited by the use of a mostly Eulerian analysis framework. Without using Lagrangian techniques, it is difficult to document the impacts of background flow conditions on the downstream weather response (Archambault et al., 2015; Bosart et al., 2017). One unexplored factor is the phase locking of an ETC with nearby troughs, which has a role in determining whether the ETC perturbation is constructive to existing Rossby waves (Riboldi et al., 2019). While our analysis does not adequately account for all of the complexity and potential forcing mechanisms involved in the relationship between ETCs and downstream weather, we provide a baseline for further research and exploration. Future work will aim to document the background flow conditions and how they influence the realization of fire weather or weather extremes in North America. Additionally, the impacts of seasonal and inter-annual climate variability on the ETC-jet stream interaction are currently unexplored and may further impact the likelihood of downstream fire weather.

\section{Declarations}

Funding: We acknowledge research funding from the U.S. Department of Energy/Office of Science under Award Number DE-SC0016605 and the SERDP project RC20-3056. Jacob Stuivenvolt-Allen and S.-Y. Simon Wang were supported by the Utah Agricultural Experiment Station, Utah State University (approved as journal paper number \#xxxx). Jacob Stuivenvolt-Allen was supported by the National Science Foundation under Grant No. 1633756.

Conflicts of interest: The authors have no conflicts of interest to declare that are relevant to the content of this article.

Availability of data and material: All data used in this study can be acquired free of charge to any member of the public.

Code availability: The code used in this study can be requested from the corresponding author, at jacob.stuivenvoltallen@usu.edu.

Author's contributions: Both authors contributed to the study concept and design. Jacob Stuivenvolt-Allen performed all analysis and writing of this manuscript. S.-Y. Simon Wang provided guidance, funding, and editing of the final manuscript.

\section{References}


1. Abatzoglou JT, Williams AP (2016) Impact of anthropogenic climate change on wildfire across western US forests. Proceedings of the National Academy of Sciences, 113(42), 11770-11775. https://doi.org/10.1073/pnas.1607171113

2. Agustí-Panareda A, Gray SL, Craig GC, Thorncroft C (2005) The Extratropical Transition of Tropical Cyclone Lili (1996) and Its Crucial Contribution to a Moderate Extratropical Development. Mon Weather Rev 133(6):1562-1573. https://doi.org/10.1175/MWR2935.1

3. Aiyyer A (2015) Recurving western North Pacific tropical cyclones and midlatitude predictability. Geophys Res Lett 42(18):7799-7807. https://doi.org/10.1002/2015GL065082

4. Archambault HM, Bosart LF, Keyser D, Cordeira JM (2013) A Climatological Analysis of the Extratropical Flow Response to Recurving Western North Pacific Tropical Cyclones. Mon Weather Rev 141(7):2325-2346. https://doi.org/10.1175/MWR-D-12-00257.1

5. Archambault HM, Keyser D, Bosart LF, Davis CA, Cordeira JM (2015) A Composite Perspective of the Extratropical Flow Response to Recurving Western North Pacific Tropical Cyclones. Mon Weather Rev 143(4):1122-1141. https://doi.org/10.1175/MWR-D-14-00270.1

6. Balch JK, Bradley BA, Abatzoglou JT, Nagy RC, Fusco EJ, Mahood AL (2017) Human-started wildfires expand the fire niche across the United States. Proceedings of the National Academy of Sciences, 114(11), 2946-2951

7. Barcikowska M, Feser F, Storch H von (2012) Usability of Best Track Data in Climate Statistics in the Western North Pacific. Mon Weather Rev 140(9):2818-2830. https://doi.org/10.1175/MWR-D-1100175.1

8. Bosart, L. F., \& Lackmann, G. M. (1995). Postlandfall Tropical Cyclone Reintensification in a Weakly Baroclinic Environment: A Case Study of Hurricane David (September 1979). Monthly Weather Review, 123(11), 3268-3291. https://doi.org/10.1175/1520-0493(1995)123<3268:PTCRIA>2.0.C0;2

9. Bosart LF, Moore BJ, Cordeira JM, Archambault HM (2017) Interactions of North Pacific Tropical, Midlatitude, and Polar Disturbances Resulting in Linked Extreme Weather Events over North America in October 2007. Mon Weather Rev 145(4):1245-1273. https://doi.org/10.1175/MWR-D-16-0230.1

10. Collins L, Bennett AF, Leonard SWJ, Penman TD (2019) Wildfire refugia in forests: Severe fire weather and drought mute the influence of topography and fuel age. Glob Change Biol 25(11):3829-3843. https://doi.org/10.1111/gcb.14735

11. Ding Q, Wang B (2005) Circumglobal Teleconnection in the Northern Hemisphere Summer. J Clim 18(17):3483-3505. https://doi.org/10.1175/JCLI3473.1

12. Evans C, Wood KM, Aberson SD, Archambault HM, Milrad SM, Bosart LF, Corbosiero KL, Davis CA, Dias Pinto JR, Doyle J, Fogarty C, Galarneau TJ, Grams CM, Griffin KS, Gyakum J, Hart RE, Kitabatake N, Lentink HS, McTaggart-Cowan R, ... Zhang F (2017) The Extratropical Transition of Tropical Cyclones. Part I: Cyclone Evolution and Direct Impacts. Mon Weather Rev 145(11):4317-4344. https://doi.org/10.1175/MWR-D-17-0027.1

13. Finocchio PM, Doyle JD (2019) How the Speed and Latitude of the Jet Stream Affect the Downstream Response to Recurving Tropical Cyclones. Mon Weather Rev 147(9):3261-3281. 
https://doi.org/10.1175/MWR-D-19-0049.1

14. Gedalof Z (2011) Climate and Spatial Patterns of Wildfire in North America. In D. McKenzie, C. Miller, \& D. A. Falk (Eds.), The Landscape Ecology of Fire (pp. 89-115). Springer Netherlands. https://doi.org/10.1007/978-94-007-0301-8_4

15. Gelaro R, McCarty W, Suárez MJ, Todling R, Molod A, Takacs L, Randles CA, Darmenov A, Bosilovich MG, Reichle R, Wargan K, Coy L, Cullather R, Draper C, Akella S, Buchard V, Conaty A, Silva AM, da, Gu W, ... Zhao B (2017) The Modern-Era Retrospective Analysis for Research and Applications, Version 2 (MERRA-2). J Clim 30(14):5419-5454. https://doi.org/10.1175/JCLI-D-16-0758.1

16. Grams CM, Jones SC, Davis CA (2013) The impact of Typhoon Jangmi (2008) on the midlatitude flow. Part II: Downstream evolution. Q J R Meteorol Soc 139(677):2165-2180. https://doi.org/10.1002/qj.2119

17. Grams CM, Lang STK, Keller JH (2015) A quantitative assessment of the sensitivity of the downstream midlatitude flow response to extratropical transition of tropical cyclones. Geophys Res Lett 42(21):9521-9529. https://doi.org/10.1002/2015GL065764

18. Harr PA, Dea JM (2009) Downstream Development Associated with the Extratropical Transition of Tropical Cyclones over the Western North Pacific. Mon Weather Rev 137(4):1295-1319. https://doi.org/10.1175/2008MWR2558.1

19. Harvey BJ (2016) Human-caused climate change is now a key driver of forest fire activity in the western United States. Proceedings of the National Academy of Sciences, 113(42), 11649-11650. https://doi.org/10.1073/pnas.1612926113

20. Hersbach H, Bell B, Berrisford P, Hirahara S, Horányi A, Muñoz-Sabater J, Nicolas J, Peubey C, Radu R, Schepers D, Simmons A, Soci C, Abdalla S, Abellan X, Balsamo G, Bechtold P, Biavati G, Bidlot J, Bonavita M, ... Thépaut J-N (2020) The ERA5 global reanalysis. Q J R Meteorol Soc 146(730):19992049. https://doi.org/10.1002/qj.3803

21. Hodyss D, Hendricks E (2010) The Resonant Excitation of Baroclinic Waves by the Divergent Circulation of Recurving Tropical Cyclones. J Atmos Sci 67(11):3600-3616. https://doi.org/10.1175/2010JAS3459.1

22. Holden ZA, Swanson A, Luce CH, Jolly WM, Maneta M, Oyler JW, Warren DA, Parsons R, Affleck D (2018) Decreasing fire season precipitation increased recent western US forest wildfire activity. Proceedings of the National Academy of Sciences, 115(36), E8349-E8357. https://doi.org/10.1073/pnas.1802316115

23. Jain P, Wang X, Flannigan MD, Jain P, Wang X, Flannigan MD (2017) Trend analysis of fire season length and extreme fire weather in North America between 1979 and 2015. International Journal of Wildland Fire 26(12):1009-1020. https://doi.org/10.1071/WF17008

24. Jones SC, Harr PA, Abraham J, Bosart LF, Bowyer PJ, Evans JL, Hanley DE, Hanstrum BN, Hart RE, Lalaurette FO, Sinclair MR, Smith RK, Thorncroft C (2003) The Extratropical Transition of Tropical Cyclones: Forecast Challenges, Current Understanding, and Future Directions. WEATHER AND FORECASTING 18:41 
25. Kanamitsu M, Ebisuzaki W, Woollen J, Yang S-K, Hnilo JJ, Fiorino M, Potter GL (2002) NCEP-DOE AMIP-II Reanalysis (R-2). Bull Am Meteor Soc 83(11):1631-1644. https://doi.org/10.1175/BAMS-8311-1631

26. Keen RM, Voelker SL, Bentz BJ, Wang S-YS, Ferrell R (2020) Stronger influence of growth rate than severity of drought stress on mortality of large ponderosa pines during the 2012-2015 California drought. Oecologia 194(3):359-370. https://doi.org/10.1007/s00442-020-04771-0

27. Krawchuk MA, Haire SL, Coop J, Parisien M-A, Whitman E, Chong G, Miller C (2016) Topographic and fire weather controls of fire refugia in forested ecosystems of northwestern North America. Ecosphere 7(12):e01632. https://doi.org/10.1002/ecs2.1632

28. Mass CF, Ovens D (2019) The Northern California Wildfires of 8-9 October 2017: The Role of a Major Downslope Wind Event. Bull Am Meteor Soc 100(2):235-256. https://doi.org/10.1175/BAMS-D-180037.1

29. Molinari, J., Knight, D., Dickinson, M., Vollaro, D., \& Skubis, S. (1997). Potential Vorticity, Easterly Waves, and Eastern Pacific Tropical Cyclogenesis. Monthly Weather Review, 125(10), 2699-2708. https://doi.org/10.1175/1520-0493(1997)125<2699:PVEWAE>2.0.C0;2

30. Orlanski I, Sheldon JP (1995) Stages in the energetics of baroclinic systems. Tellus A 47(5):605628. https://doi.org/10.1034/j.1600-0870.1995.00108.x

31. Pantillon F, Chaboureau J-P, Lac C, Mascart P (2013) On the role of a Rossby wave train during the extratropical transition of hurricane Helene (2006). Q J R Meteorol Soc 139(671):370-386. https://doi.org/10.1002/qj.1974

32. Riboldi J, Grams CM, Riemer M, Archambault HM (2019) A Phase Locking Perspective on Rossby Wave Amplification and Atmospheric Blocking Downstream of Recurving Western North Pacific Tropical Cyclones. Mon Weather Rev 147(2):567-589. https://doi.org/10.1175/MWR-D-18-0271.1

33. Riemer M, Jones SC (2010) The downstream impact of tropical cyclones on a developing baroclinic wave in idealized scenarios of extratropical transition. Q J R Meteorol Soc 136(648):617-637. https://doi.org/10.1002/qj.605

34. Schoennagel T, Veblen TT, Kulakowski D, Holz A (2007) Multidecadal Climate Variability and Climate Interactions Affect Subalpine Fire Occurrence, Western Colorado (usa). Ecology 88(11):2891-2902. https://doi.org/10.1890/06-1860.1

35. Seager R, Hooks A, Williams AP, Cook B, Nakamura J, Henderson N (2015) Climatology, Variability, and Trends in the U.S. Vapor Pressure Deficit, an Important Fire-Related Meteorological Quantity. Journal of Applied Meteorology Climatology 54(6):1121-1141. https://doi.org/10.1175/JAMC-D-140321.1

36. Stuivenvolt Allen J, Wang S-YS, LaPlante MD, Yoon J-H (2021) Three Western Pacific Typhoons Strengthened Fire Weather in the Recent Northwest U.S. Conflagration. Geophys Res Lett 48(3):e2020GL091430. https://doi.org/10.1029/2020GL091430

37. Wagner CEV, Forest P, Station E, Ontario CR, Franï ¿1/2ais RUE, Davis HJ (1987) Development and Structure of the Canadian Forest FireWeather Index System. Can. For. Serv., Forestry Tech. Rep 
38. Wallace, J. M., Zhang, Y., \& Lau, K.-H. (1993). Structure and Seasonality of Interannual and Interdecadal Variability of the Geopotential Height and Temperature Fields in the Northern Hemisphere Troposphere. Journal of Climate, 6(11), 2063-2082. https://doi.org/10.1175/15200442(1993)006<2063:SASOIA>2.0.C0;2

39. Westerling AL (2016) Increasing western US forest wildfire activity: Sensitivity to changes in the timing of spring. Philosophical Transactions of the Royal Society B: Biological Sciences 371(1696):20150178. https://doi.org/10.1098/rstb.2015.0178

40. Westerling AL, Swetnam TW (2003) Interannual to decadal drought and wildfire in the western United States. Eos Transactions American Geophysical Union 84(49):545-555.

https://doi.org/10.1029/2003E0490001

41. Yoon J-H, Kravitz B, Rasch PJ, Wang S-YS, Gillies RR, Hipps L (2015) Extreme Fire Season in California: A Glimpse Into the Future? Bull Am Meteor Soc 96(12):S5-S9. https://doi.org/10.1175/BAMS-D-15-00114.1

\section{Figures}

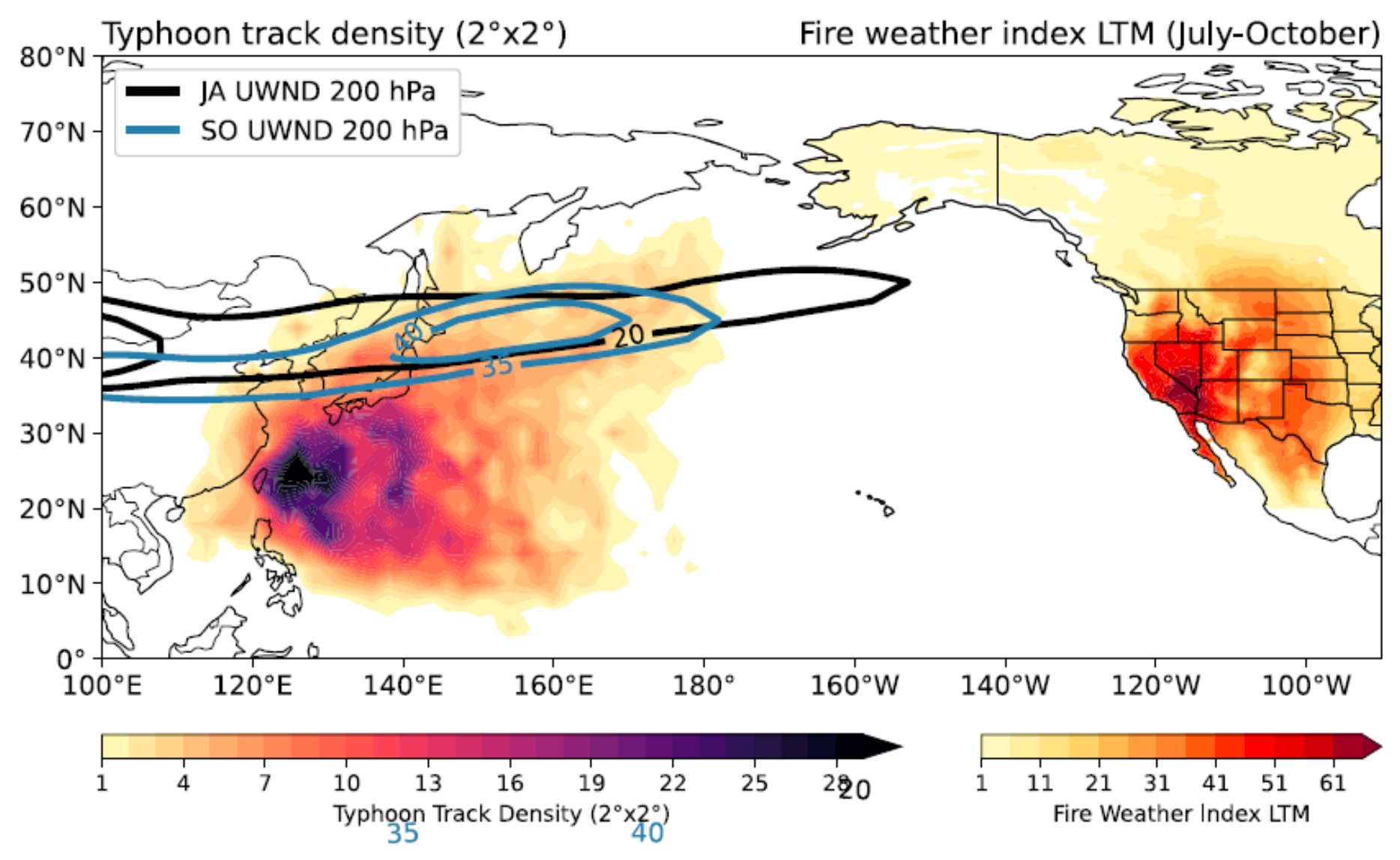

Figure 1

Typhoon track density (shading in the western Pacific) of ETCs along with the long-term mean jet stream (1981-2010) for JA and SO (contours). The shading over North America represents the long-term mean 

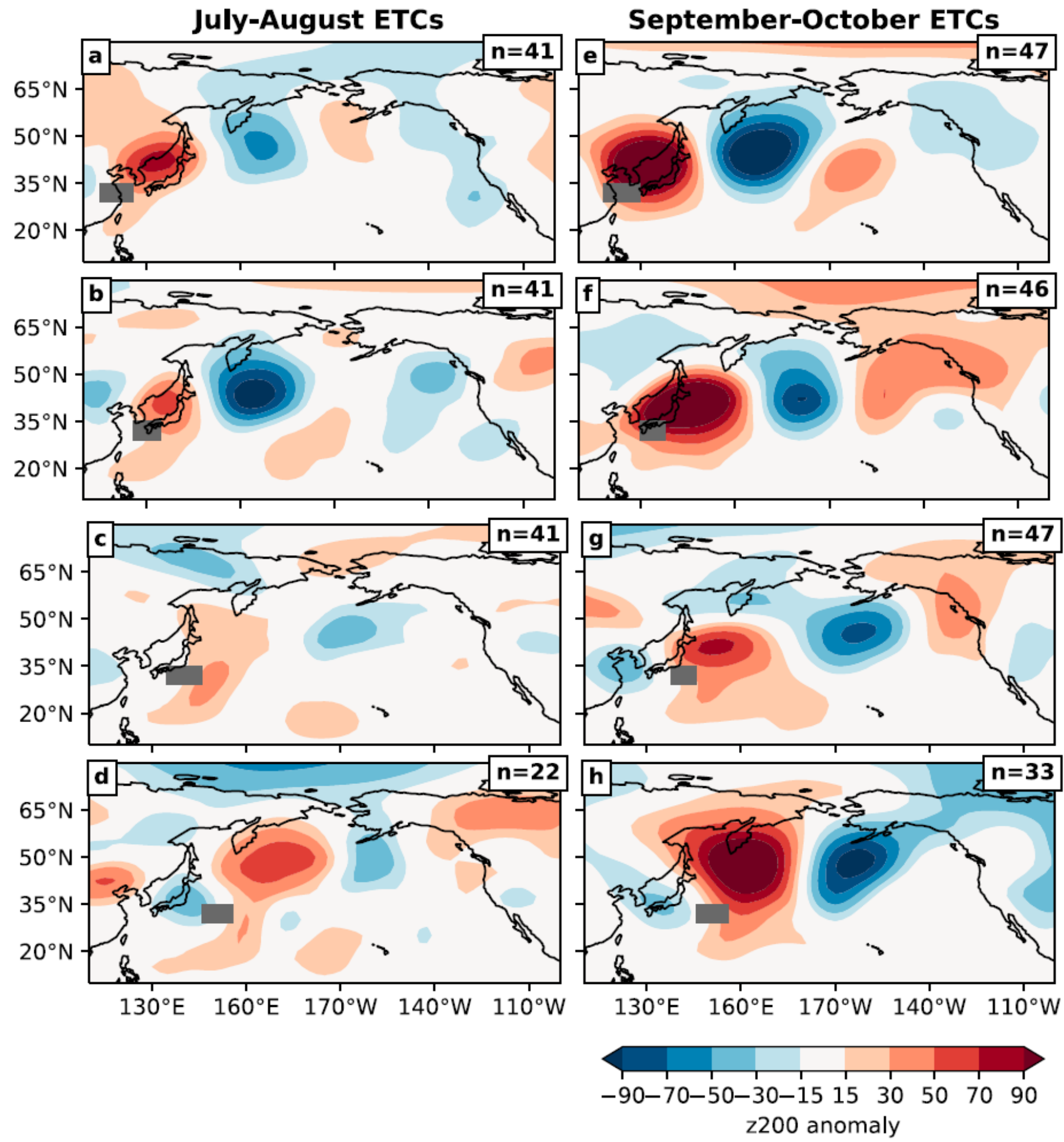

Figure 2

Composite z200 and associated with ETCs for JA (a-d) and SO (e-h) for the day that T0 occurred. The gray boxes indicate the quartile ranges for TO longitude for the respective season. 

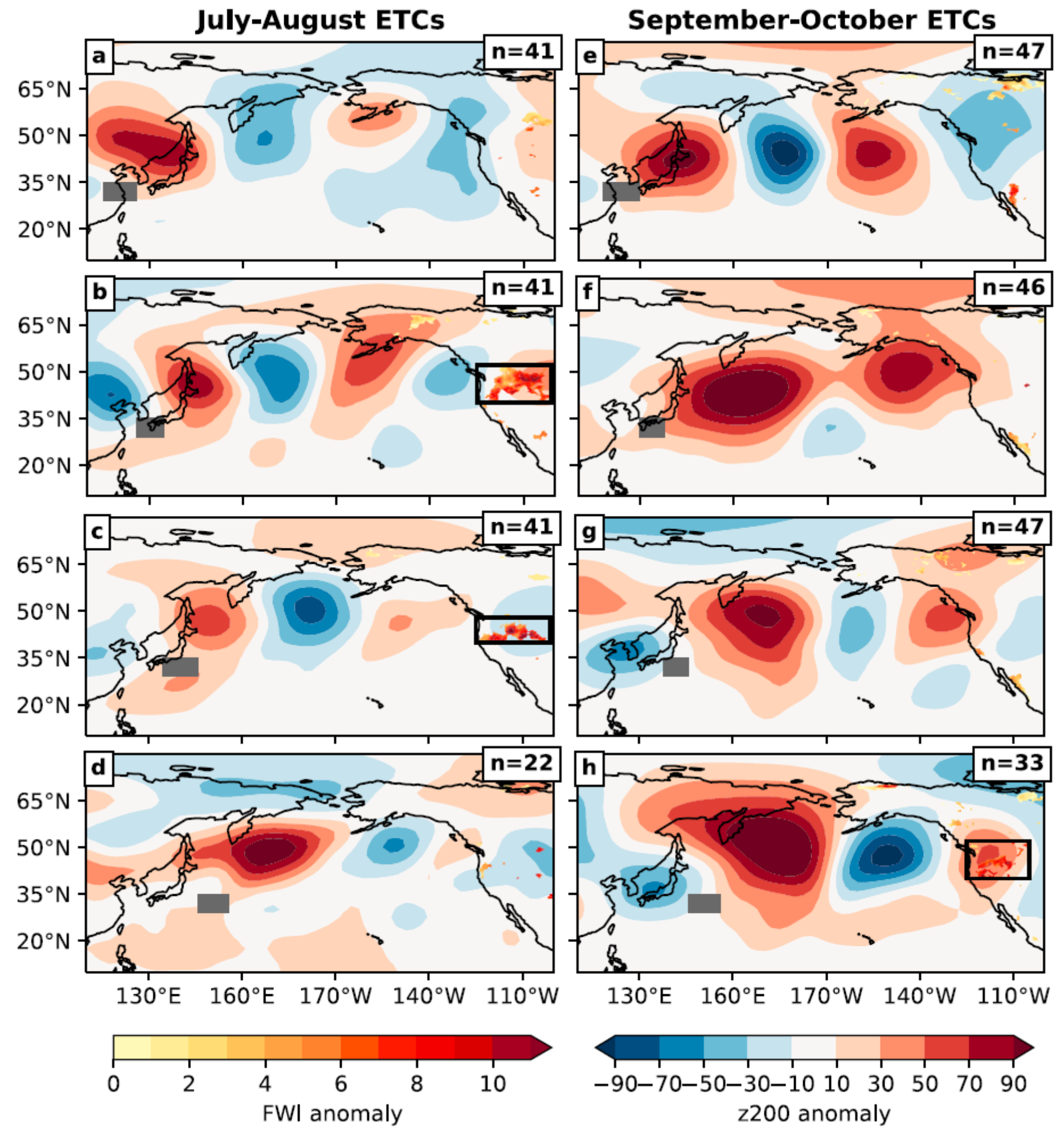

\section{Figure 3}

Composite z200 and FWI associated with ETCs for JA (a-d) and SO (e-h) for 2 days after T0. The gray boxes indicate the interquartile ranges for TO longitude for the respective season. A student's $t$ test is used to determine which areas have mean FWI values that are significantly different at 2 days after T0 the 2 days before T0. Only values which surpass the $90 \%$ confidence interval are shown for FWI. 
Composite members for July-August ETCs: 2nd longitude IQR

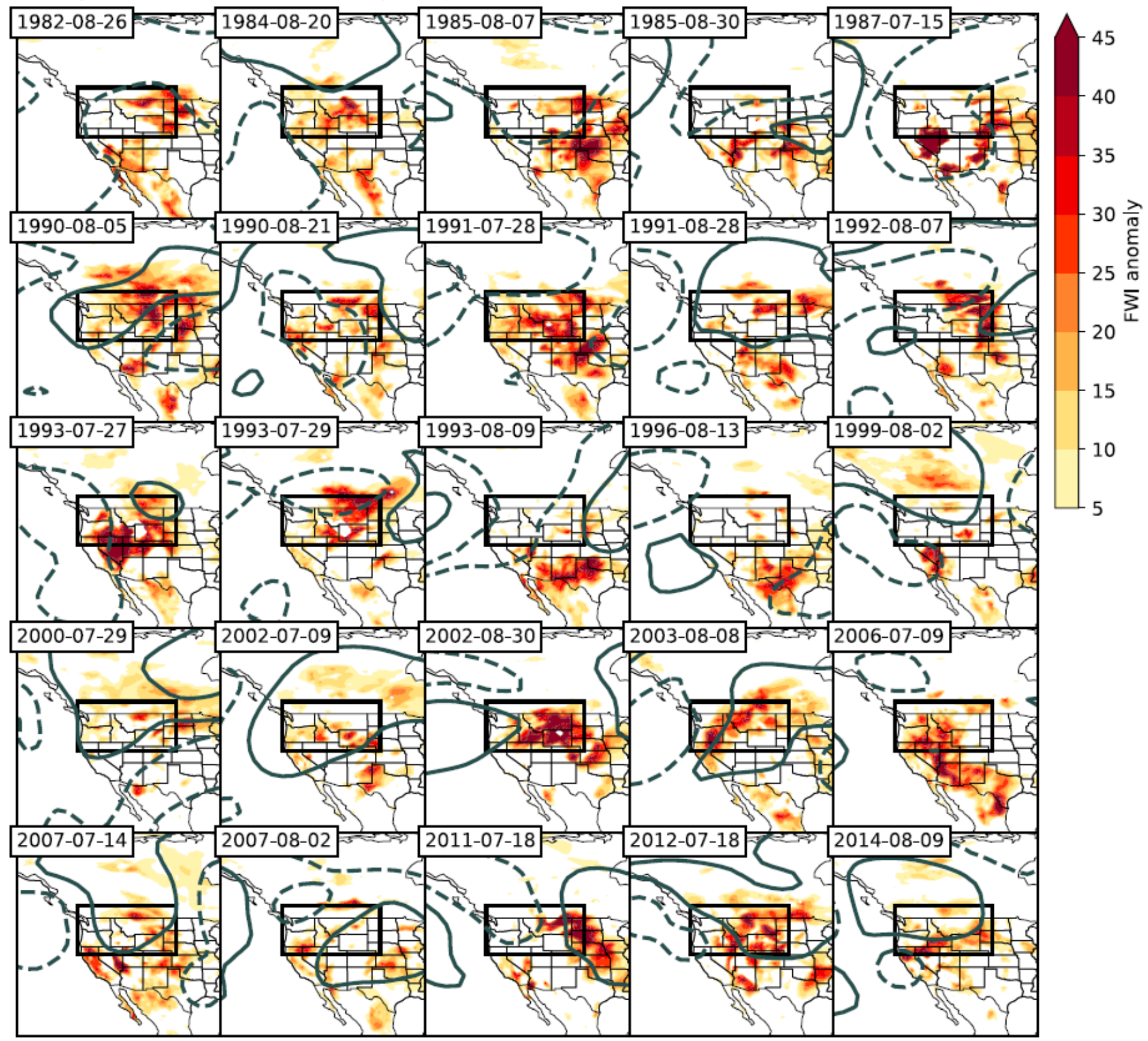

Figure 4

FWI and z200 anomalies associated with twenty-five composite members chosen at random from the 2nd IQR of ETC longitude for JA. The solid and dashed contour lines respectively indicate a 70 meter and -70 meter anomaly in z200 from the daily long term mean. The black rectangle highlights the region in which the composite analysis resulted in a statistically significant difference in FWI from before and after TO. 
Composite members for SO ETCs: 2nd longitude IQR

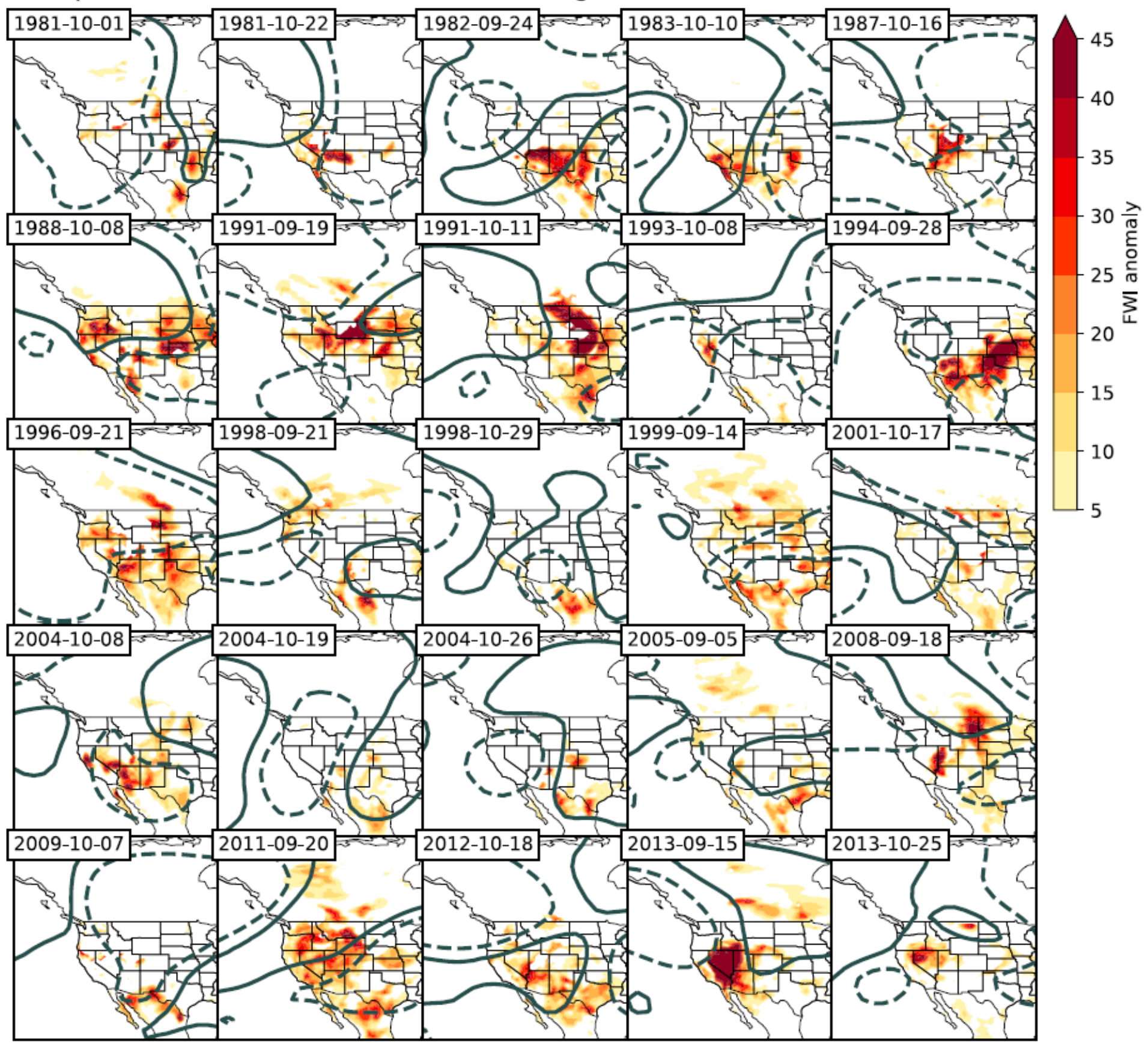

Figure 5

Same as Figure 4, but for the 2nd longitudinal IQR of SO. 

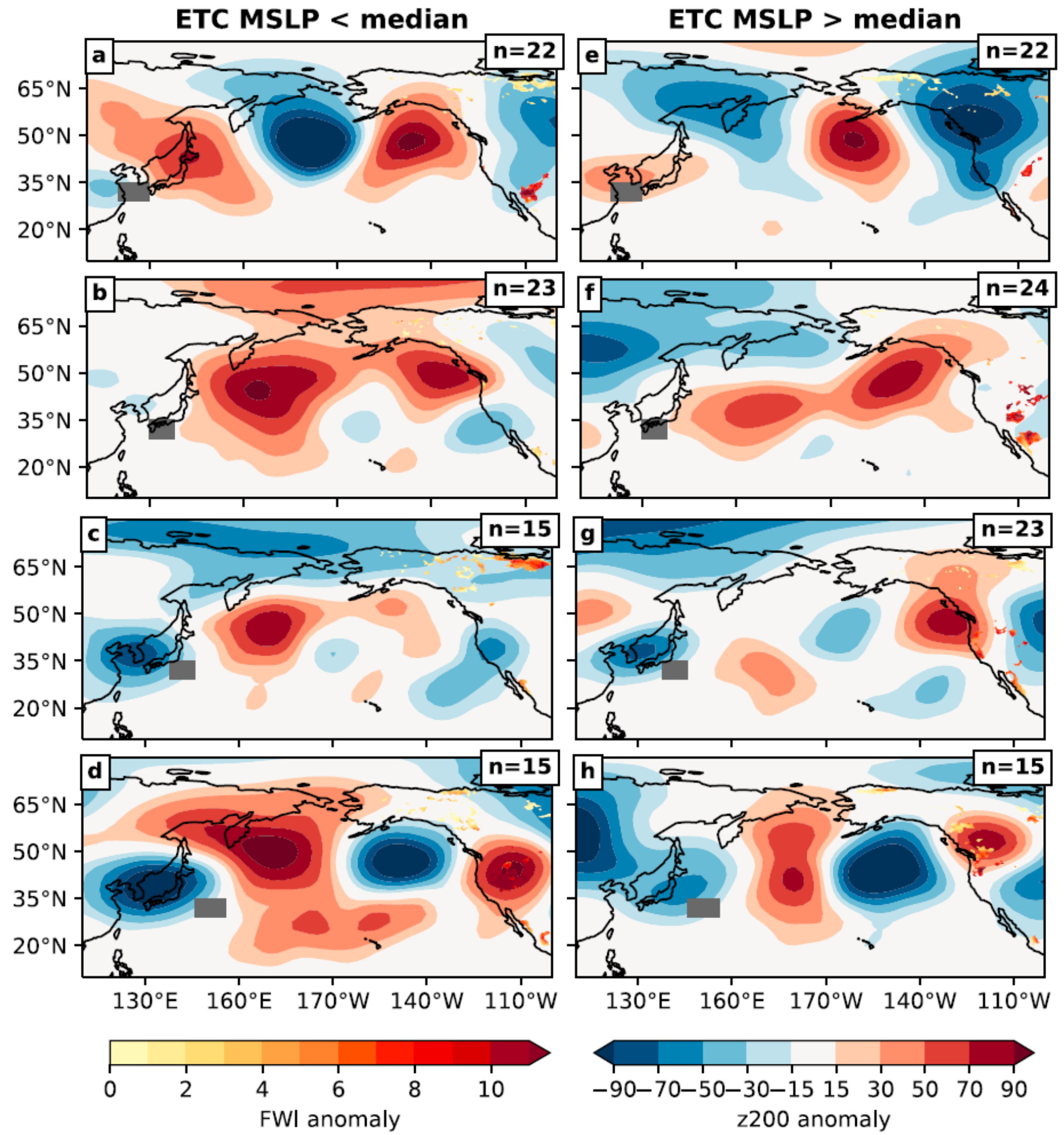

\section{Figure 6}

Composite z200 and FWI associated with ETCs which occurred in SO. Figures 6a-d are composites anomalies of z200 and FWI two days after T0 for ETCs with a central MSLP below the median for each longitudinal IQR. Figures 6e-h show the composite response for ETCs with a central MSLP greater than the median for each longitudinal IQR. The gray boxes indicate the quartile ranges for T0 longitude for the respective season. Only FWI values which surpass the $90 \%$ confidence interval are shown. 
a) Strong jet interaction: JA

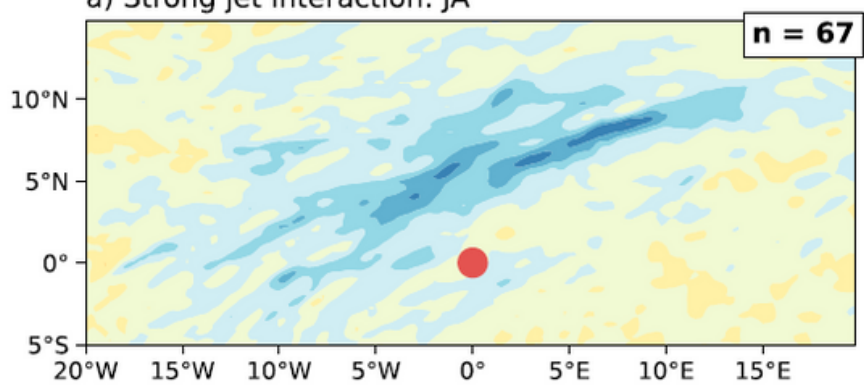

C) Strong jet interaction: $\mathrm{SO}$

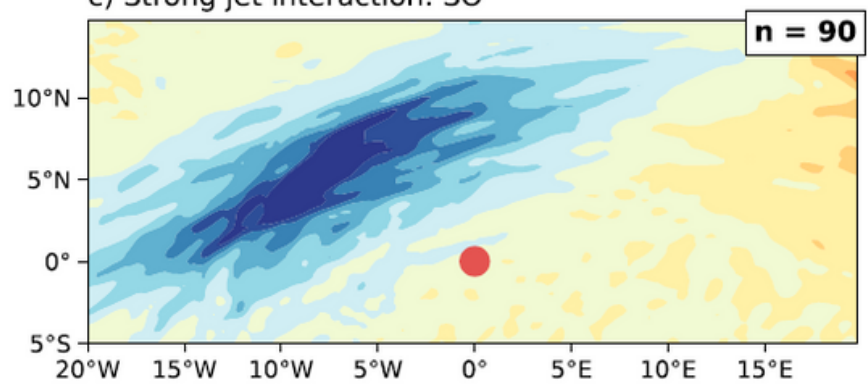

b) Weak jet interaction: JA

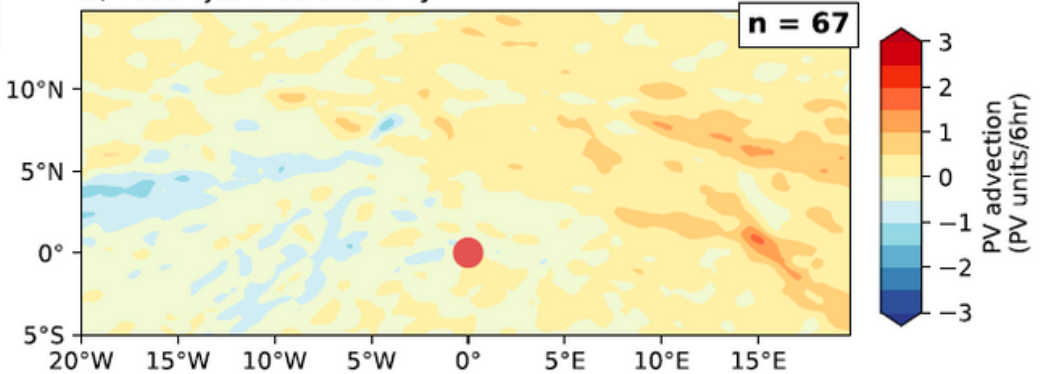

d) Weak jet interaction: SO

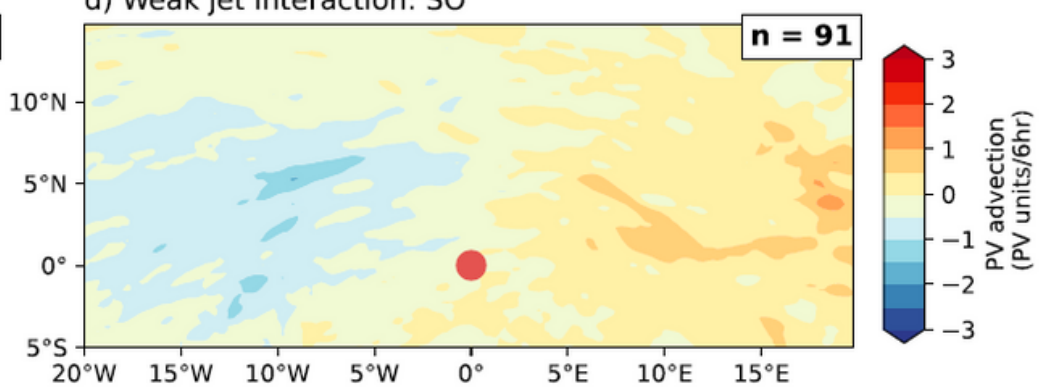

\section{Figure 7}

Average PV advection for ETCs with a strong jet interaction (a, negative PV advection less than the median) and a weak jet interaction ( $b$, negative PV advection greater than the median) during JA $(a, b)$ and $S O(c, d)$. The contour plot shows the PV advection relative to the center of the ETC, represented by the red dot. PV is represented by PV units, which is defined as m2s-1K kg-1 multiplied by $1.0 \mathrm{e} 6$. Note that the contour range is increased for the SO composites. 

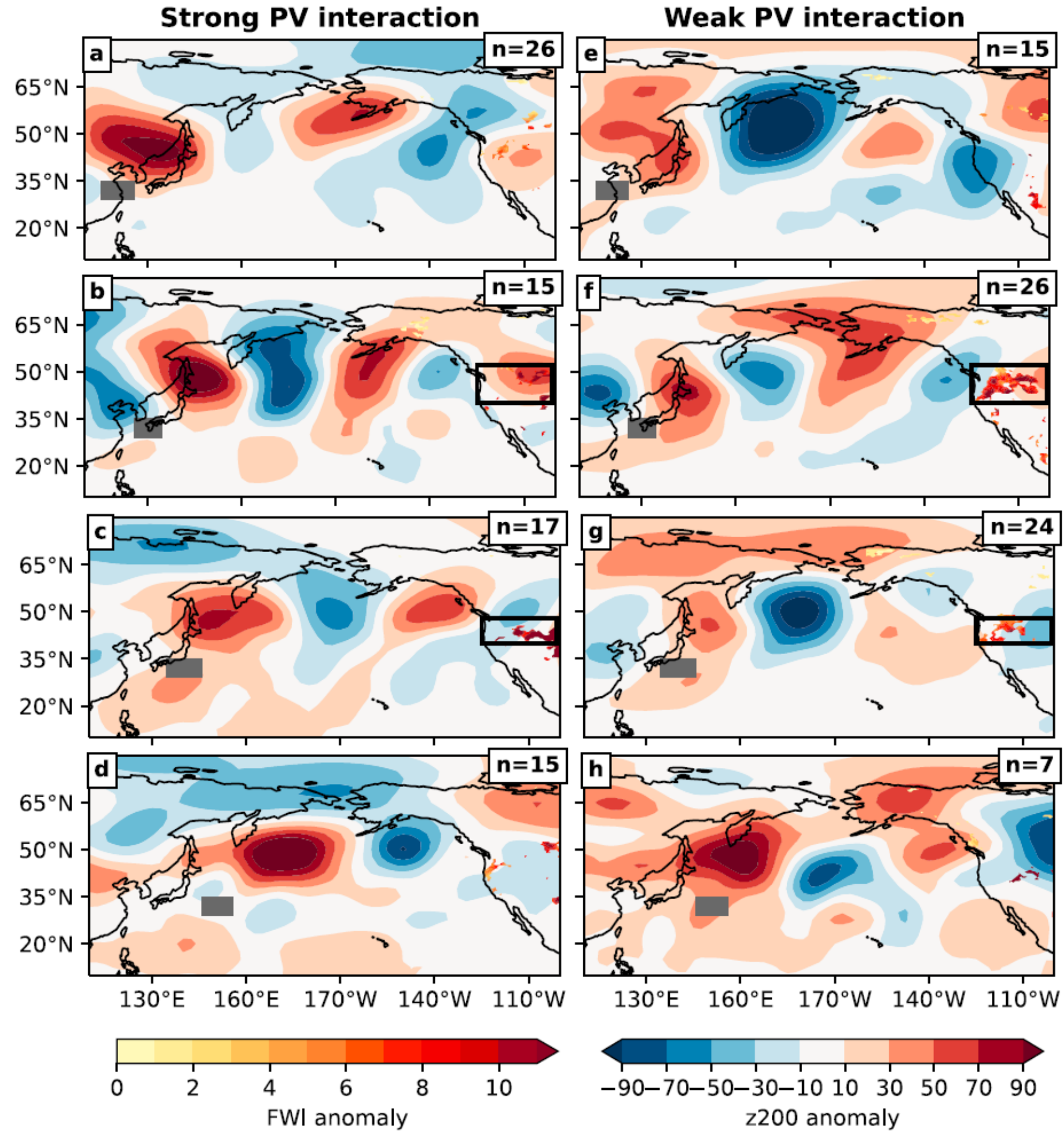

Figure 8

Composite z200 and FWI associated with ETCs which occurred in JA. Figures 8a-d are composites anomalies of z200 and FWI two days after T0 for ETCs characterized by a strong jet interaction. Figures 6e-h show the composite response for ETCs with a weak jet interaction. The gray boxes indicate the quartile ranges for T0 longitude for the respective season. Only values which surpass the $90 \%$ confidence interval are shown for FWI. 


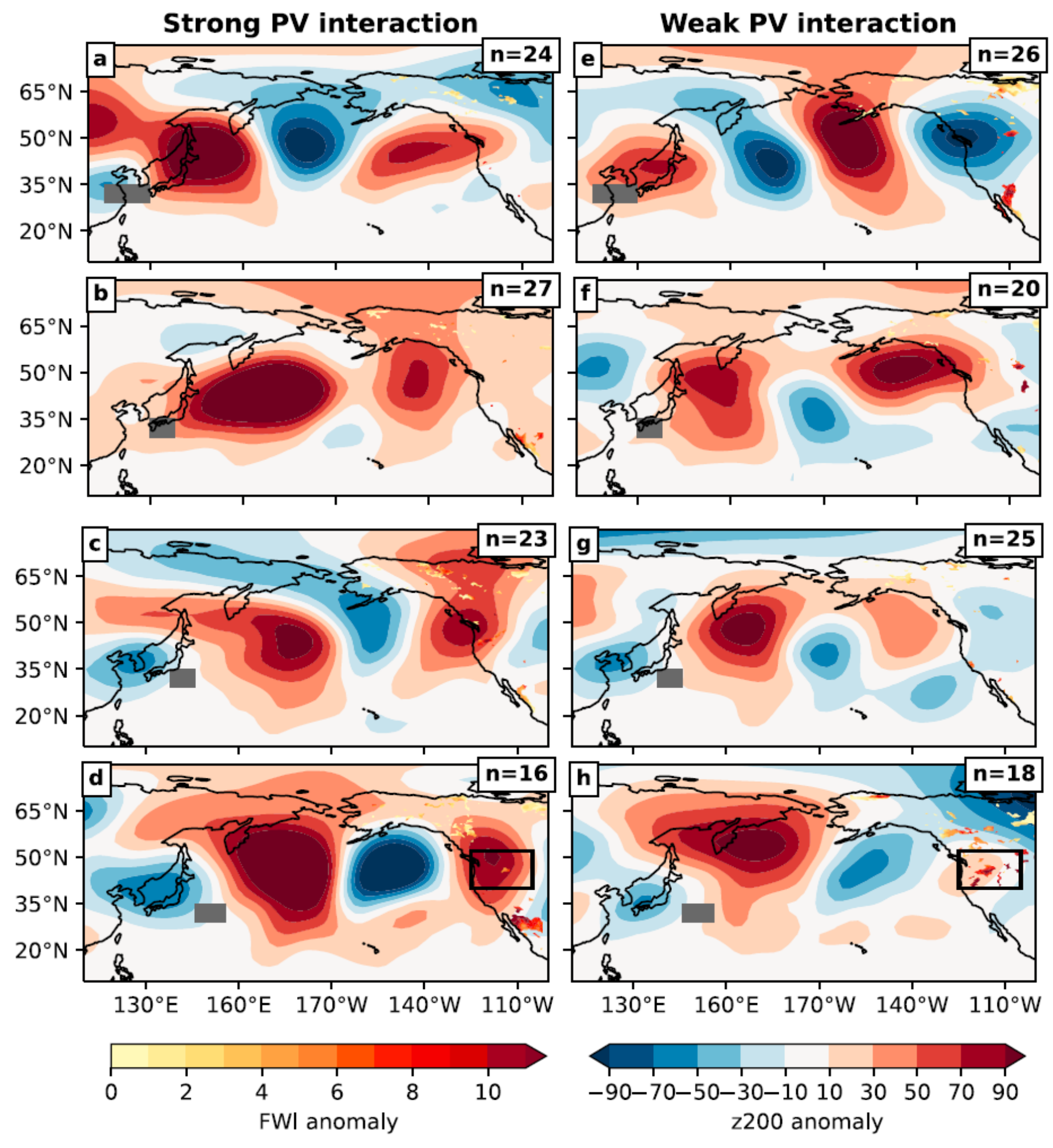

Figure 9

Same as Figure 8 but for the SO ETCs. 
a) Fire Weather Index
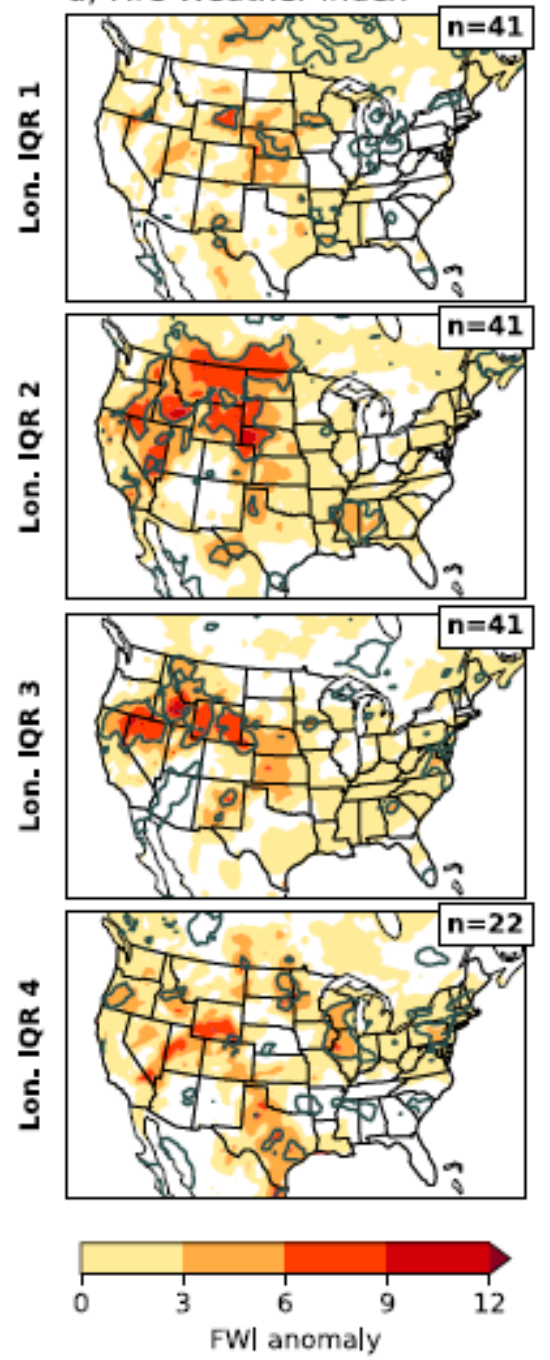

b) Initial Spread Index
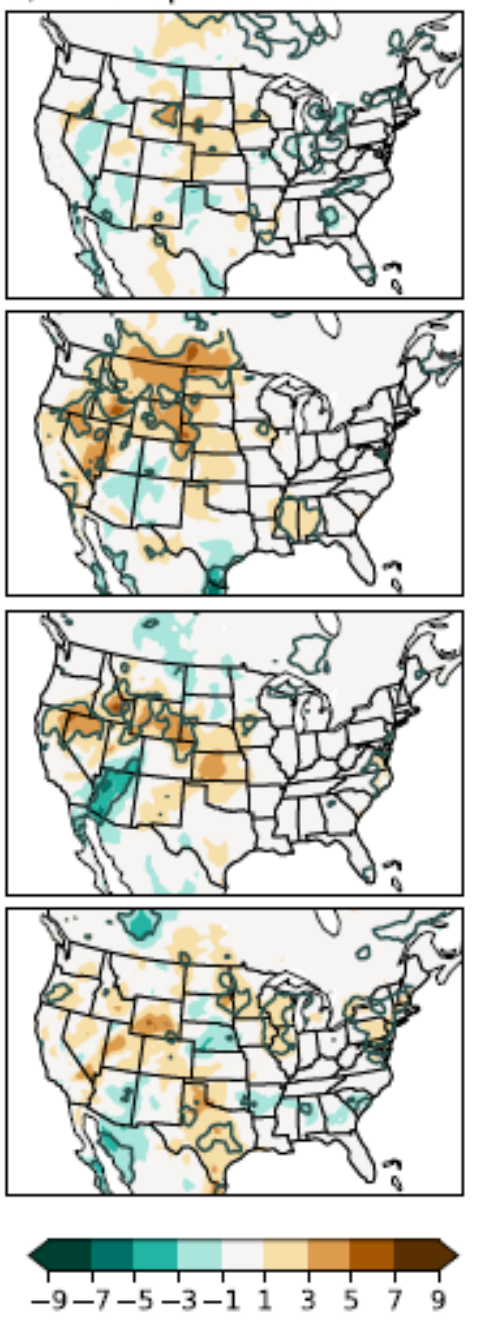

ISI anomaly c) Buildup Index
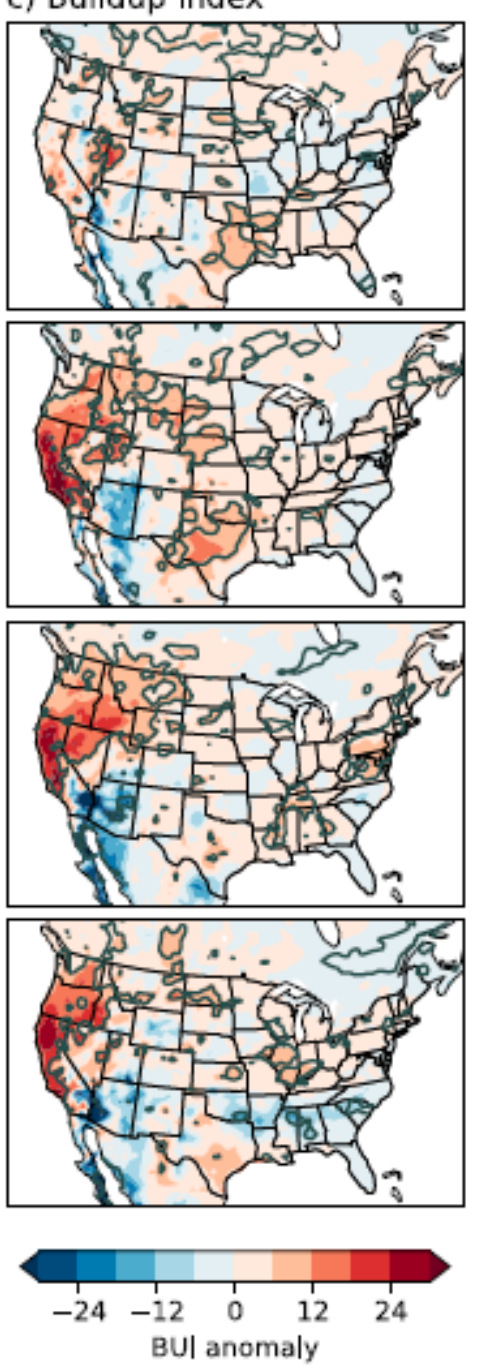

Figure 10

Composite FWI (10a), ISI (10b) and BUI (10c) associated with JA ETCs at each longitudinal IQR. Each anomaly represents the difference in between the fire index three to four days after T0 and three to two days before T0. The contours indicate regions where the change in each fire index is significantly different at the $90 \%$ confidence level than the period before T0. 
a) Fire Weather Index
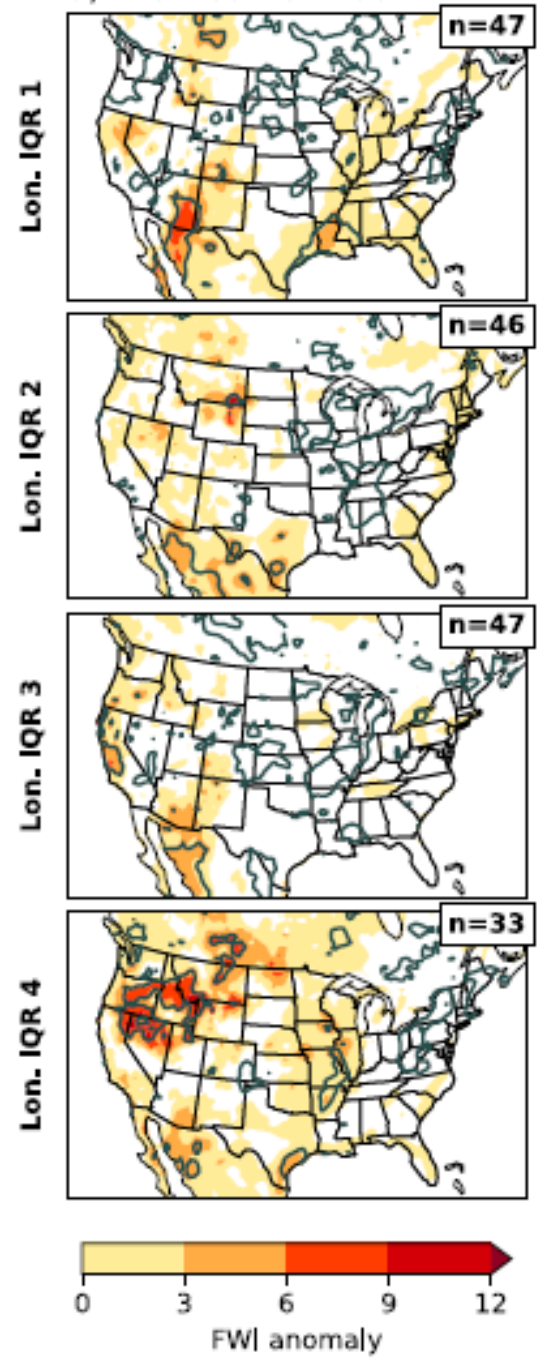

b) Initial Spread Index
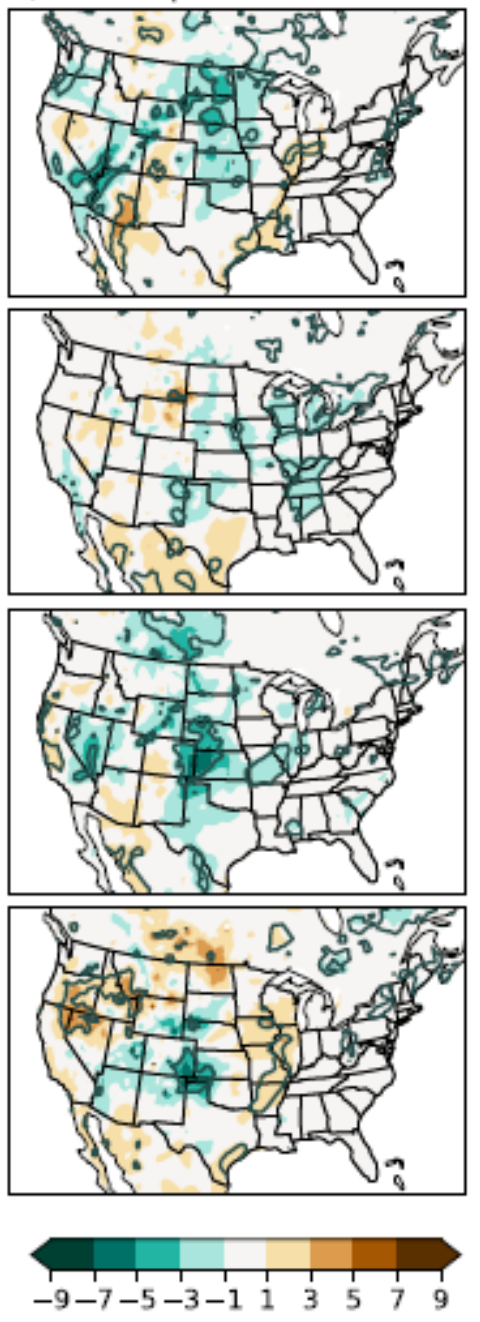

IS| anomaly c) Buildup Index
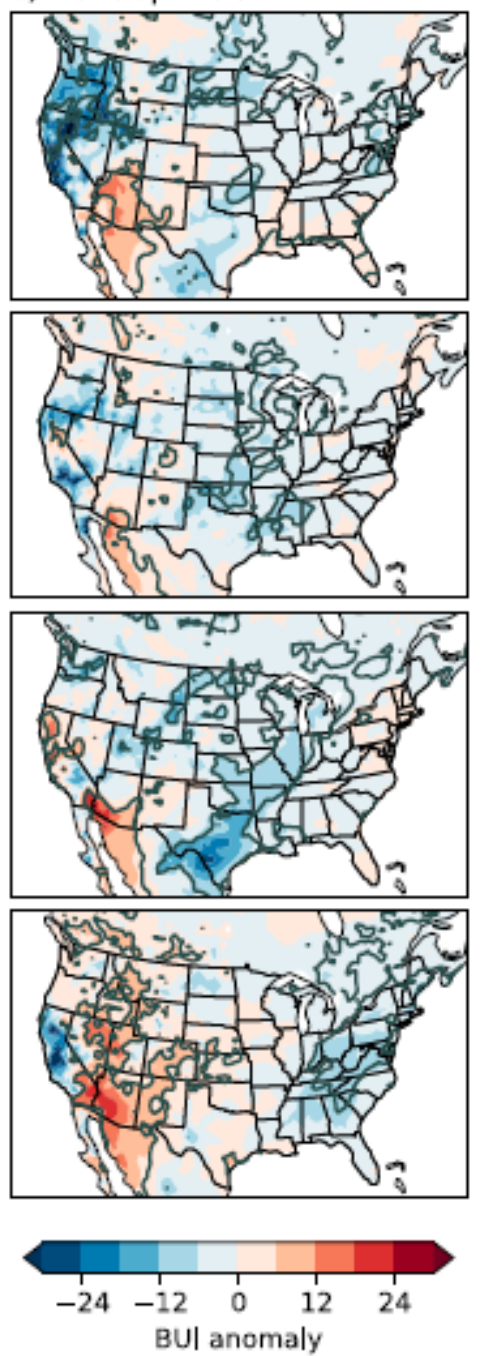

Figure 11

Composite FWI (11a), ISI (11b) and BUI (11c) associated with SO ETCs at each longitudinal IQR. Each anomaly represents the difference in between the fire index two days after T0 and two days before T0. The contours indicate regions where the change in each fire index is significantly different at the $90 \%$ confidence level than the period before TO.

\section{Supplementary Files}

This is a list of supplementary files associated with this preprint. Click to download.

- FIGS1.eps 